\title{
Sustainable Waterfront Development-A Case Study of Bahary in Alexandria, Egypt
}

\author{
Riham A. Ragheb \\ Department of Architectural Engineering, Faculty of Engineering, Pharos University, Alexandria 21311, Egypt
}

\begin{abstract}
Sustainable waterfront development is about creating a vision for an area and then deploying the skills and resources to realize it after involving a dialogue with the customer within an area. Also, it draws together many strands of place making such as environmental responsibility, social equity and economic viability, planning and transportation policy, architectural design into the creation of places of beauty and distinct identity. The development of waterfronts shapes communities around the water bodies and reflects the ability of cities to adapt to altered economic and social circumstances. The aim of this paper is to identify some approaches for applying sustainable waterfront development. By respecting the quality of life and defining sustainability in a broader context, a case will be made for enhancing the waterfront development, through the place making criteria, analyzing the Bahary waterfront in Alexandria, Egypt. The paper concludes some recommendations to develop Bahary waterfront based on the principles that are collected from the theoretical study in order to well design a waterfront responded to the wishes of the community.
\end{abstract}

Key words: Place making, quality of life, Bahary, sustainable waterfront development.

\section{Introduction}

The waterfront is a unique and irreplaceable resource, also, its boundaries are difficult to determine because they are contained mixed use development, which is relatively homogeneous. Thus, it can be characterized as a place integrating land with water and having a natural attraction to people [1]. The waterfronts can be regarded in terms of property that has a strong visual or physical connection to water [2]. Also, waterfront properties may not necessarily need to be directly fronting water but are tied to it visually or are linked to it as a part of a larger scheme [3].

This paper is based on three approaches: theoretical, applied and analytical study. The theoretical study tends to cover the concept of waterfront development, and then identify the sustainable waterfront development such as the sustainable development principles, the quality of life indicators and place making criteria. This is followed by an applied study of Bahary, Alexandria in Egypt, and its context and

Corresponding author: Riham A. Ragheb, lecturer; research field: architecture. E-mail: riham.ragheb@pua.edu.eg. potentials by the application of the sustainable waterfront development approaches are analyzed. Then the paper concludes the important recommendations to improve this area in order to achieve sustainable waterfront development.

\section{Waterfront Development}

There are several meanings of waterfront development which vary according to the characteristics of sites and cities. Waterfront development has a number of expressions such as "waterfront regeneration" [4], "waterfront revitalization" [5], and "waterfront redevelopment" [6]. Waterfront development is a process that begins due to the desires of a community to improve its waterfront which contains mixed use development that is relatively consistent.

While, the scale and type of the waterfront redevelopment varies from city to city, the basic concept of development is similar. There are three categories of waterfront development on different levels which help to elucidate the meaning of waterfront development [1]: 
- Waterside development is local and environmental planning which puts emphasis on the water-human relationship design and the waterfront remedy, and its objective is to create an accessible and enjoyable water environment;

- Waterfront development is urban planning which puts emphasis on the feasibility study of the development projects and the spatial design, and its objective is renewal and development of the urban areas;

- Coastal development is national planning which puts emphasis on the development strategies and the implementation of planning, and its objective is to prescribe the character of the city and the development scheme.

\subsection{Importance of Waterfront Development}

Waterfronts are a special class of national resource due to their unique potential in affording society diversified opportunities for economic development, public enjoyment, and civic identity. They have become the focus of many issues created by the changing technologies and the pressures of population and commerce. The nature and uses of waterfronts have changed and left large sections of waterfront land unused or under used. Therefore, the development of waterfront areas has become a challenge to affect the identity and environmental quality of cities. Waterfronts have been called romantic and used as places for dreaming and recreation, also waterfronts left the feelings of openness and freedom that tend to be everybody's place. The presence of water in cities is an element of attraction and holds out the hope of a better life.

\subsection{Types of Waterfront Development}

A city must first and foremost determine what it intends its waterfront to be. These issues must be sorted out before a city can plan for the redevelopment of its waterfront. In a trend of transforming the waterfronts to vibrant zones of leisure, commerce and housing by waterfront development [3], there are a number of conventional types:

\subsubsection{Major Waterfront Transformations}

Major waterfront transformations are unique that meet the needs and aspirations of cities that are unlike in geography, history and character. They share many factors such as housing, shopping, offices and recreation. There are complex negotiations, dedicated leadership and huge sums of public and private money are involved to accomplish the transformations.

\subsubsection{The Commercial Waterfront}

There are a variety of project typifies the dynamism of the commercial waterfront to encourage public enjoyment of the waterfront. These projects include "festival marketplace" which is widespread and longstanding tradition of eating, shopping and socializing along water bodies, likewise is a public focal point, drawing people to attend many events.

2.2.3 The Cultural, Educational and Environmental Waterfront

The cultural, educational and environmental waterfront emphasizes the vital connections between people and water and can have a real effect on the way they think about this basic resource which man and natural are inseparable parts of the unified whole.

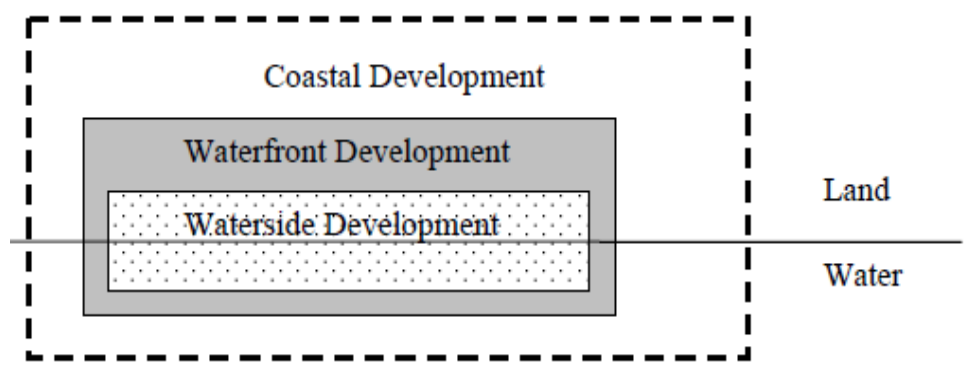

The interface betweet

land and water

Fig. 1 The three categories of waterfront development [1]. 
Waterfronts have been providing beautiful setting for religious architecture, memorials, public art and grand cultural institutions and educational sites for generations.

\subsubsection{The Historic Waterfront}

Instead of condemning old waterfront structures to non-use, decay and ultimate abandonment, some cities are working toward the preservation and adaptive reuse of historic buildings that maintains a tangible sense of the past and favoring a restorative approach that makes for a richer community and captures the allure that comes from being in touch with the past in modern daily life.

\subsubsection{The Recreational Waterfront}

Spending a leisure time on the water, whether for fishing, swimming or quiet contemplation is the recent theme of the urban waterfront development around the globe. Also, creating public spaces such as parks, marinas, walkways and promenades with shade pavilions, distinctive paving and lighted fountains constitute the biggest change along today's urban waterfront, add a pleasant atmosphere and provide relaxation and enjoyment with being on the waterfront.

\subsubsection{The Residential Waterfront}

People throughout history have been living along the water for reasons both practical and poetic which housing styles varied according to the culture. Water, rivers, lakes, coasts and canals are public resources; the space along the water's edge is welcoming balanced to visitors as well as to residential population. This means that walkways and facilities are visible, attractive and accessible and comfortable for the residents.

\subsection{Waterfront Development Process}

The opportunity for the urban waterfront development exists when the difference in an existing property's value and its value in a changed state exceeds the cost of the conversion. Waterfront development process goes through different phases which are [7]:

2.3.1 The Pre-development Phase

The pre-development phase includes project initiation, project analysis, prepares the preliminary design and project packaging toward identifying opportunities for the development. During this phase, it is important to reevaluate the development concept and refine the program in light of changing circumstances and new information, research, comprehensive analysis, and calculations of time range and cost of activities involved to fully realize the development.

\subsubsection{The Development Phase}

The development process focuses on design, financing and implementation. While these basic tasks transform a project proposal into physical reality, the timing of financial support and the activities of the professional designers and building contractors must be carefully coordinated to produce the project that meets the objectives.

\subsubsection{Post Development Phase}

The post development activities are determined to extent the long-term viability. Although the managing and maintaining requirements of the waterfront projects are identified before the start of construction, the general trend agreements for public/private development projects must clearly define which party will be responsible for the management and maintenance and who will pay the cost.

\section{Waterfront Development Approaches}

High quality, well designed and managed urban spaces play a crucial role in promoting wellbeing and contribute positive social, economic and environmental value to cities for any improvement, development and future monitoring. Public open spaces have positive associations with people's quality of life, health, well-being and their feelings. Therefore, a better understanding of the links between the quality of public spaces and quality of life is vital to justify greater development and improving public 
realm. The public realm is where most of human contact and interaction take place and its character will reinforce the public place. Therefore, it is important to achieve what really matters to people and develop the sense of place by creating a public realm and built environment that are of the highest quality. Also, commercial viability, tourist attractions, livability and sustainability are important factors to take into consideration to provide a better quality of life for the city [8]

Several approaches discuss the benefits of a well designed built environment and its effect on many aspects of daily lives. There are clear denominators that link the different approaches that focus on the human wellbeing. Attractive and open mixed use urban spaces with good accessibility encourage leisure activities and reduce crime and vandalism. Quality of life, sustainability, and place making criteria are a multidisciplinary philosophy incorporating many different fields. They are the process of creating places where people feel safe, happy, and at home. To achieve a great place making, it is necessary to requir sustainability and quality of life criteria which are implemented by various principles. In order to analyze a waterfront case study, it is important to set the following principles to well design a waterfront.

\subsection{The Quality of Life Indicators}

Quality of life is a relatively impressionistic and a multidimensional concept which means different things to different people [9]. The optimal level of quality of life is produced by combining the physical and psychological inputs. The quality of life can be translated through social and environmental considerations in the process of urban planning and is affected by the place in which we live. The concept of quality of life includes subjective or qualitative phenomena at the individual and the community level as well as objective measures of the status of individuals and the community [10].

The interest in quality of life comes from city leaders and different parties including those who are interested in human development, social development, sustainable development and healthy communities. Thus, quality of life is important because a lot of people and organizations are paying attention to it. There is a concern to measure the quality of life of cities and understand how we are doing and feeling [10].

In the past few decades, social scientists have attempted to objectively measure the quality of urban life through a variety of quantifiable social indicators which have been structured around the social/cultural, economic and environmental wellbeing to maintain and improve quality of life in urban spaces. These indicators are: natural and living environment, overall experience of life, governance and basic rights, health, education, economic and physical safety, leisure and social interactions, productive or main activity and material living conditions [11].

\subsection{The Place Making Criteria}

Great public spaces are those places where celebrations are held, social and economic exchanges occur, friends meet, and cultures mix [12]. The public places need to be unique, attractive, colorful, related to the human-scale and have different contexts such as historical, geographical, physical or cultural. The places as streets, open spaces or seafronts can be designed visually and functionally, through sensitive and imaginative design to provide a feeling of well-being or comfort [8]. Engineering, architecture, landscape architecture, urban planning, social work, journalism, and public administration have improved the urban physical environment to incorporate knowledge and ideas acquired from the social and physical sciences on dealing with some of the social problems associated with urbanization [13]. Therefore, the process of place making allows diverse constituencies to identify how public spaces can be shaped to make them welcoming, well-functioning and attractive places for people. One of the most 
critical factors in achieving a public space that truly serves its constituents, improve the daily experience and draws people time and again, is by asking people about their concerns and wishes and allowing them to influence decision-making about that space.

More than just promoting better urban design, place making strengthens facilitates creative patterns of use, paying particular attention to the physical, cultural, and social identities that define a place and support its ongoing evolution. According to public spaces which are a nonprofit planning, design and educational organization, public spaces have four major attributes to evaluate a place and measure its success which are: access and linkages, uses and activities, comfort and image, and sociability [12]:

\subsubsection{Access and Linkages}

A place has to be well connected to its surroundings visually and physically and easy to get to and to get through. Also, the edges of a space are important as well and the place has to have a high parking turnover which is convenient to public transit [14].

\subsubsection{Comfort and Image}

The key of a successful space is to be comfortable and have a good image. Comfort includes perceptions about safety, cleanliness, and the availability of places to give people the choice to sit where they want [14].

Fig. 2 The quality of life indicators [11].
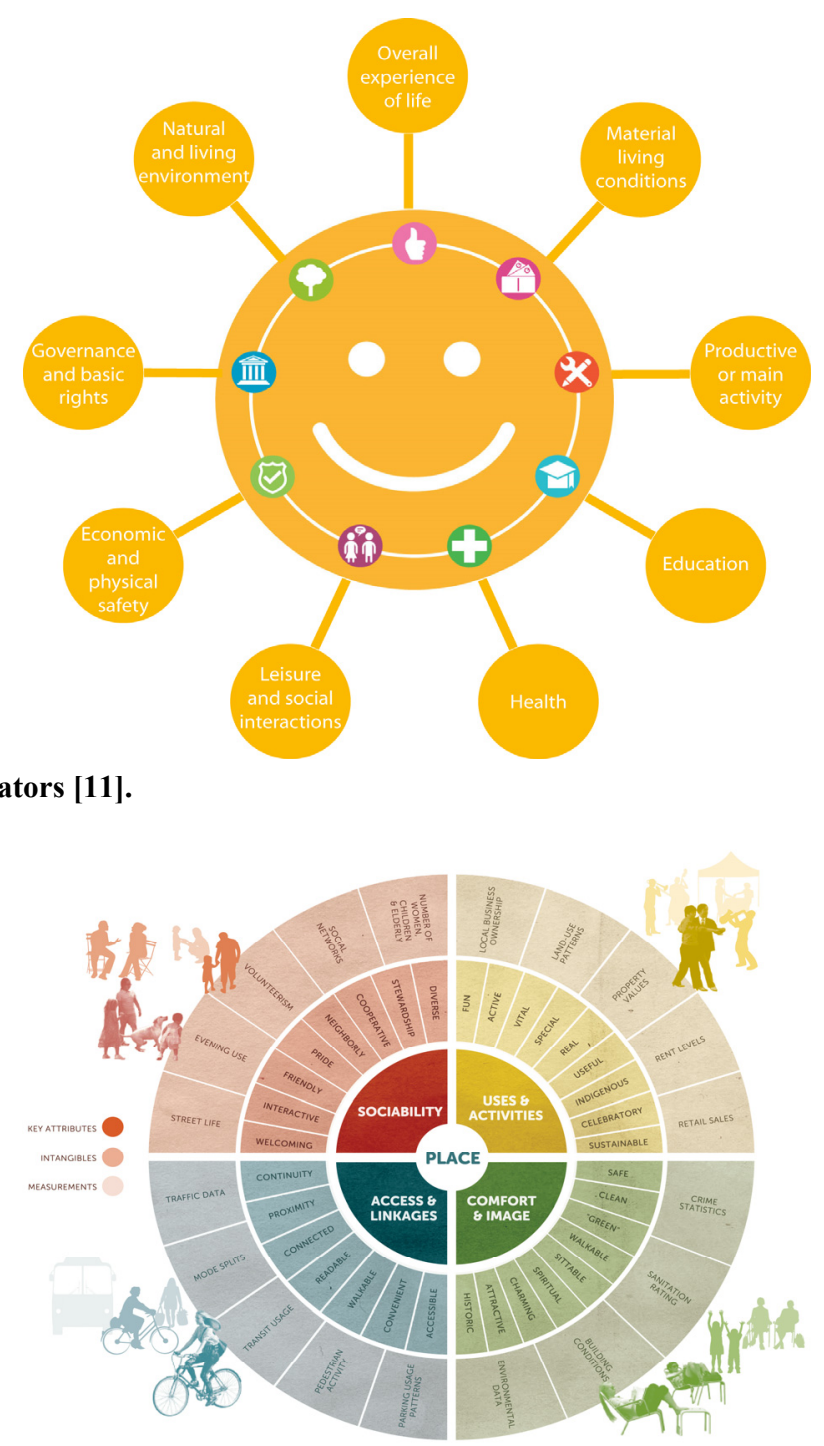

Fig. 3 The place making criteria [12]. 


\subsubsection{Uses and Activities}

Uses and activities are the basic building blocks of a place. Having some activities to do in the place gives people a cause to come and return. It is important to provide various well managed activities throughout the day for people of different ages, to be used by singles or people in groups [14].

\subsubsection{Sociability}

When people see friends, meet their neighbors, and feel comfortable interacting with guests, they tend to feel a stronger sense of place or attachment to the place that fosters these types of social activities. This is a difficult quality for a place to achieve, but once attained, it becomes an unmistakable feature [14].

\subsection{Sustainable Development Principles}

Sustainable development projects are a key component of the transformation of urban environments. In such urban environments, waterfronts present themselves as a very particular case. The declining and neglected waterfronts constitute highly potential targets for transformation into new and refined patterns of land uses through the development projects while aiming for a high quality of life, nourishment of business and conservation of the environment. Waterfront development schemes necessarily involve the principles of sustainability: economic, social, environmental, and preservation [3].

\subsubsection{Economic}

The deindustrialization of city centers has resulted in many changes in technology, and thus has caused many industrial places and ports to relocate. Some cities shift their industrial places and activities from cities to suburbs. This relocation has left the existing waterfronts land freed up for development.

\subsubsection{Social}

The global culture today requires more open spaces for recreation and physical needs. Generally, more mobility has caused an expansion of tourism. This may encourage the installation of new mixed uses along the water bodies that combine areas of open space and leisure, with shops, café and restaurants and provide cultural and recreational attraction.

\subsubsection{Environmental}

Since the 1970s, there has been an emphasis on the environmental issues that include cleaning up water bodies, water supply, natural marine life and pollution. This demand is to protect the environment, and encourage new waterfront investment.

\subsubsection{Preservation}

The trend toward cultural tourism pushes to make value to the historical building. Preservation and restoration are important to give a character to the city. The similar element in waterfront development around the world is the public's desire to be near to the water. Most existing waterfront areas which have not yet been discovered are either remains of industrial areas and slum areas. These areas may become fashionable places to live in, and can promote more investments [3]. In dealing with the development of waterfronts, they are classified into three categories [15]:

- The first one is "conservation" which aims to use the site of an old waterfront, which still exists even today, and restores it for the people;

- The second category is "redevelopment", which is characterized by an attempt to resurrect the waterfront as important areas of urban life;

- The third is "development", which is an attempt to create a waterfront which will meet the present needs of the city.

\section{The Gomrok District}

Alexandria city extends today some $60 \mathrm{~km}$ along the Mediterranean coast, but its breadth is limited to an average of 1 to $5 \mathrm{~km}$. It encompassed an area of $2,680 \mathrm{~km}^{2}$. Residential land use is the most dominant in the urban area, but it is difficult to segregate residential land use from other urban functions. Commerce and workshops are often completely mixed with the residential use. The city of Alexandria is divided into six districts: Montazah District, Eastern District, Middle District, Gomrok District, Western 
District and Amriya District.

The Gomrok District with total area of $4 \mathrm{~km}^{2}$ is considered the smallest area with the highest population density with a rate of increase of $1.17 \%$ per year.

\subsection{Historical Background}

Alexandria was founded by Alexander the Great in
April 331 BC, Alexandria became the capital of the Greco-Roman Egypt, its status as a beacon of culture symbolized by Pharos; the famous lighthouse. Dinocrates built the Heptastadion, the causeway between Pharos and the mainland. This divided the harbors into the Western and Eastern [14]. Of modern Alexandria, the oldest section is along the causeway which links what was once Pharos island with the

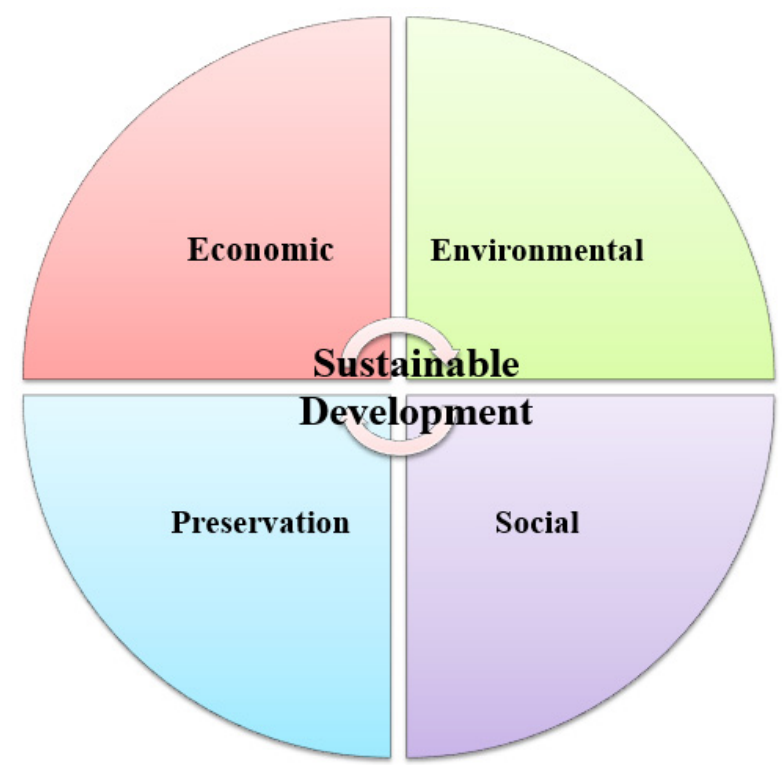

Fig. 4 The sustainable development principles.

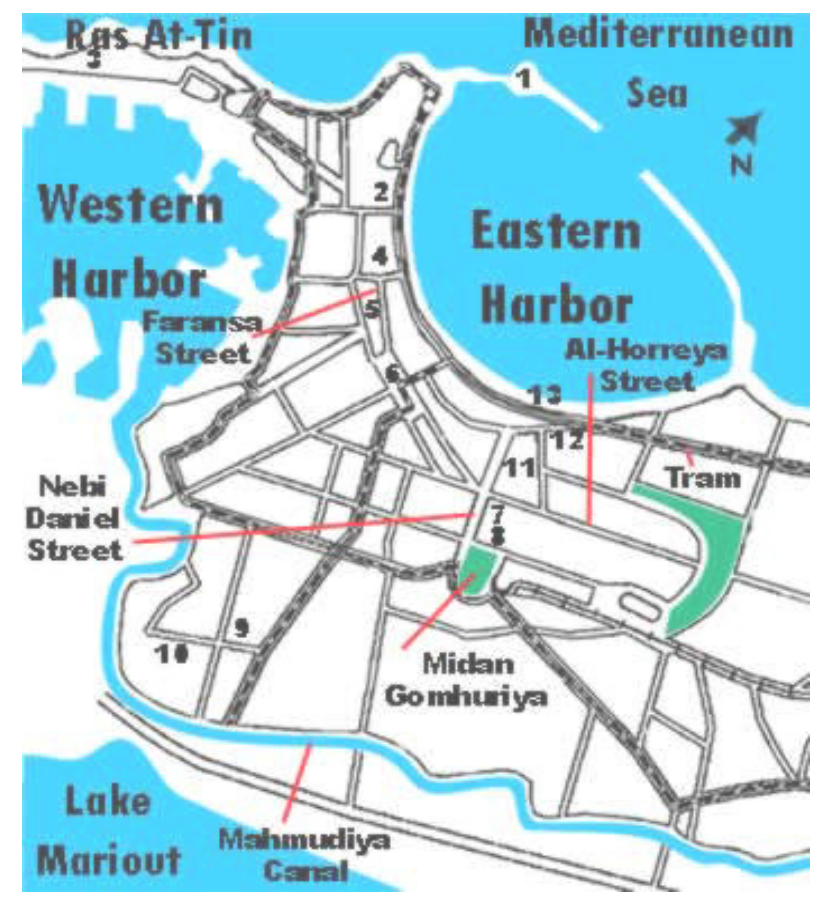

Fig. 5 The map of old Alexandria [16]. 


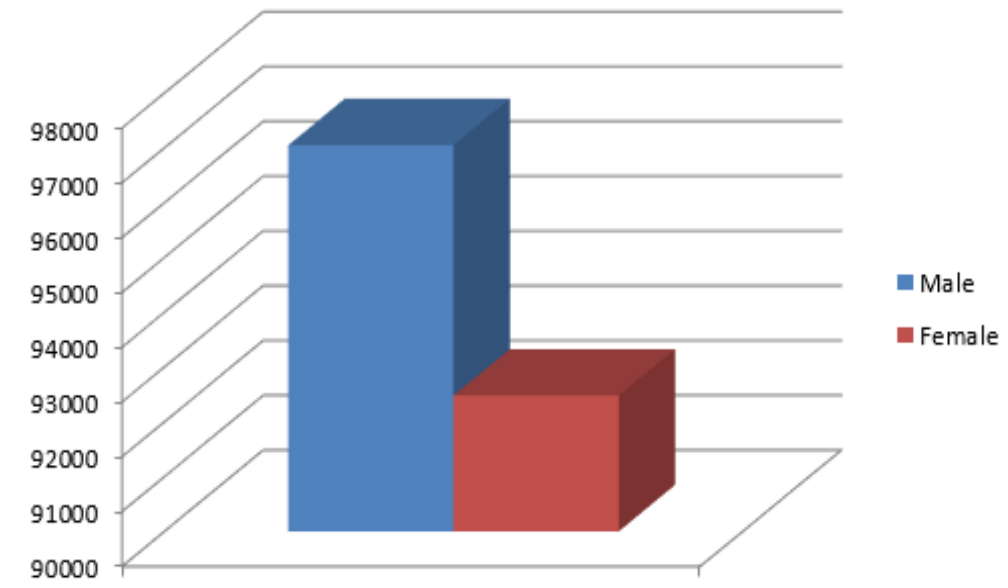

Fig. 6 The distribution of the population.

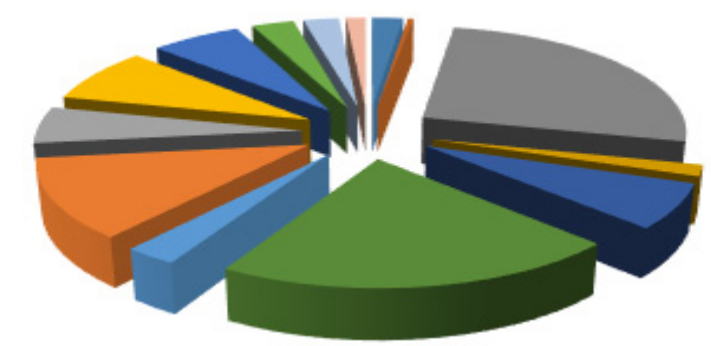

\section{Agriculture \& fishing mining \& quarries \\ Manufacturing \\ Electricity, gas \& water supply}

Fig. 7 Manpower studies classification according to the occupations.

mainland and includes the districts of Gomrok that includes Anfushi, and Ras el-Tin that are known to westerners as the Turkish Quarter. The area forms somewhat of a T-shape, dividing the Eastern Harbor from the Western Harbor [16].

\subsection{Climatic Conditions}

Due to the geographical location for the Mediterranean Sea. The latter has apparently an influential impact as it is related to the enjoyment of the moderate climatic conditions of the study area which is suitable for human life throughout the year.

\subsection{Population of the Gomrok District}

The Gomrok District is considered the smallest area of Alexandria with the highest density with an area of 622 acres and the current population is 123 thousand people-intensive public 191 people/acre.

\subsection{The Land Use of the Gomrok District}

Gomrok District is a mixed-use reaching a rate of about 58\% residential use and the proportion of economic activities increases the proportion of services for up to about $17.4 \%$. In addition, the existing physical environment is considered a problem due to its degradation and the marine pollution.

\subsection{Monuments and Ancient Sites in Gomrok District}

There are many monuments and ancient sites. Some of them are highlighted in Fig. 8

\section{Bahary Study Area}

Bahary waterfront in Bahary, Kasr Ras El Tin, is classified as a main street in the street network of 


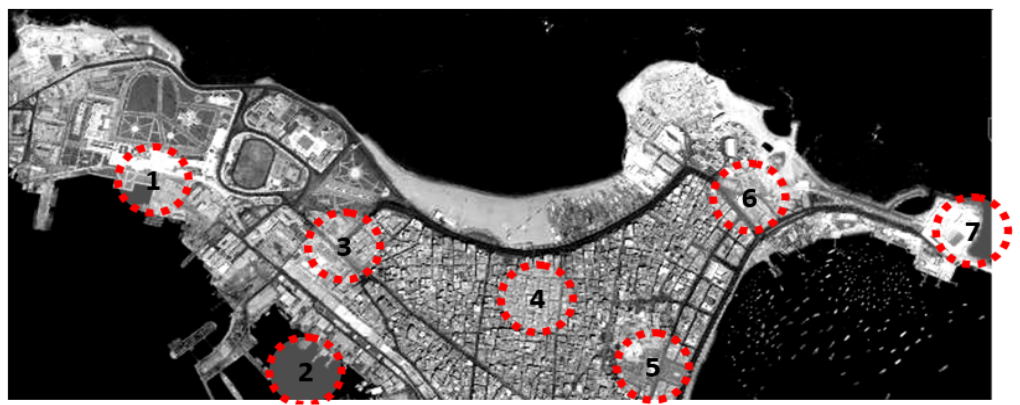

Fig. 8 Map of monumental and ancient sites.
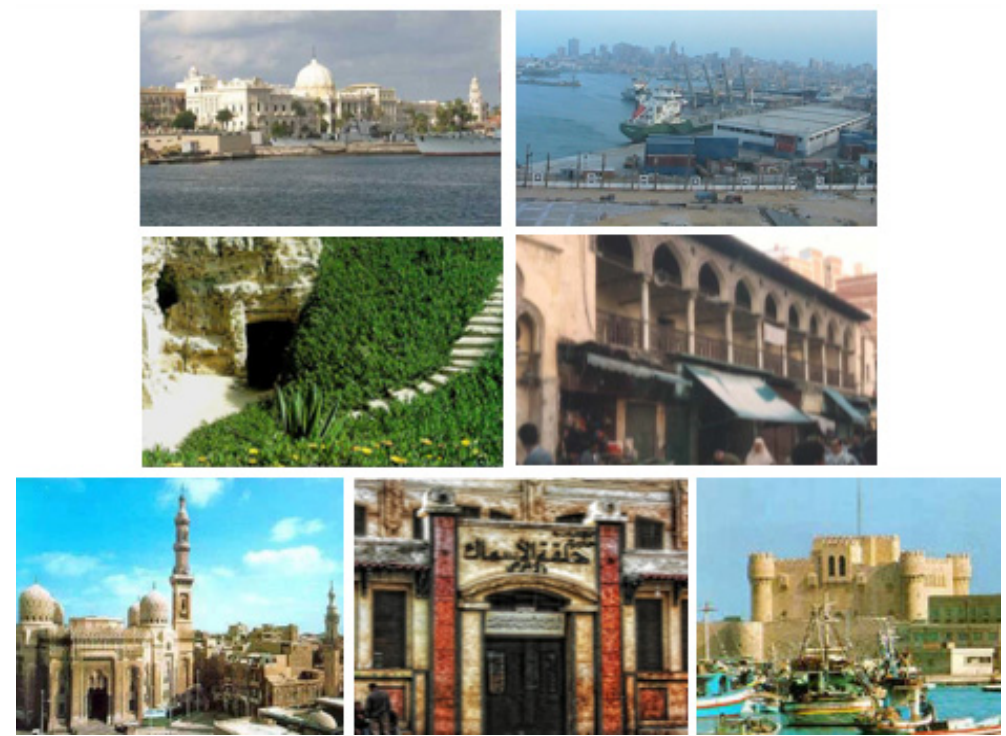

Fig. 9 Pictures of the famous sites by order: Ras EI Tin Palace; Alexandria Port; El Anfoushy Ptolemic Tombs; Commercial area in the Turkish quartier; Abu El-Abbas Mosque; Anfoushy Fish Market; Fort of Qaitbay.

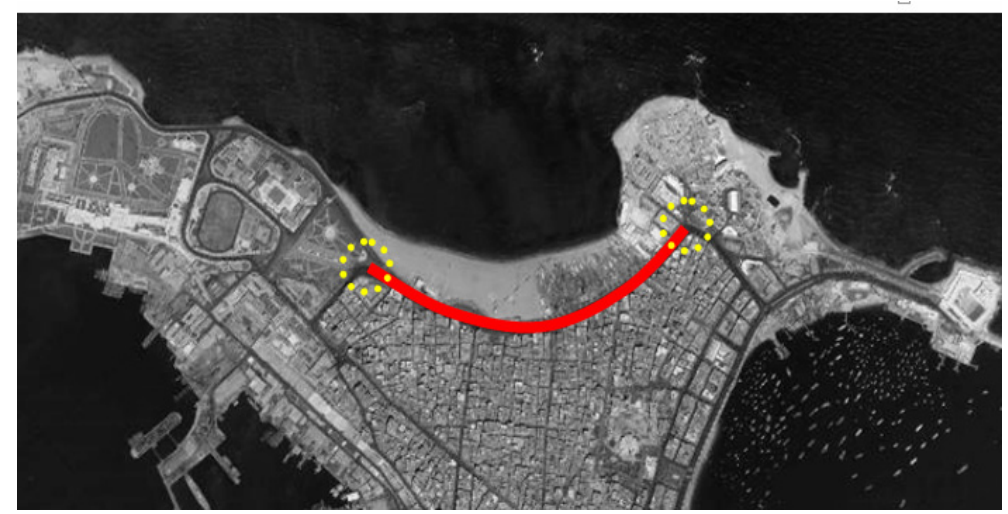

Fig. 10 Map showing the study area.

Alexandria. The Mediterranean Sea presents its waterfront to the north. The study area will focus on the coast which represents The Anfoushy Public beach and the costal hinterland that represents Kasr Ras el Tin Street which leads to Ras El-Tin Palace, which is allocated for the reception of official delegations of the state. It also holds the function as a main gate to the Turkish quarter, which unfortunately began to gradually disappear due to the neglecting of this area's building. Any waterfront development process goes through different phases. This study focuses on the pre-development phase. 


\subsection{Analysis of Bahary Waterfront}

Bahary has a waterfront scenic path, with prominent views of the Anfoushy Bay and Ras El Tin Palace. It is also with a historic background as it is the main entrance to the old Turkish Town of Alexandria, which includes a unique urban pattern of houses and streets. The analysis of study area is based on some principles collected during the theoretical part which focuses on the principles of waterfront development.

\subsubsection{Access and Linkages}

The waterfront stretches $900 \mathrm{~m}$ along the sea and with variable width, from $25 \mathrm{~m}$ to $37 \mathrm{~m}$, joins the El Gish Road in the east to the very narrow streets of the old city in the west, and it is the only main street which serves the connection of its surrounding area land uses to the rest of Alexandria. At the southern street perimeter, there are more than 30 T-intersections with small and poor local streets, mostly with dead ends as well as some secondary streets like Sidi El-Hagary Street, Safr Basha Street, and Sidi Yacout Street. Also, there is a promenade along the sea but it does not encourage the public access and it was lined by palm trees to provide shade and there is a safety railing and lighting units along the walkway. The waterfront can be accessed by different means of transportation: public bus, private car, horse cart, bicycles and boats. The city tram, of which the network serves the old city, runs with other traffic in the middle of its right-of-way. Hiring boats or horse cart are considered as tourist attraction. Furthermore, the waterfront esplanade leads to various activities and attractions such as historical buildings, restaurant, the Anfoushy cultural center and the boats workshops that had run for decades.

The presence of variable activities and street level uses on the pedestrian paths are important to achieve walkability and vitality in the city

In addition, multiple accesses to the waterfront provide a good accessibility to the different landmarks in this areas: Palace Ras El Tin, The Anfoushy fish market and the boat workshops are connected by the
Kasr Ras El Tin Street and el Morsy Abo El Abbas Mosque is permeable by Sidi Yakout Street. Walkable waterfront with activities are necessary to connect various destinations in order to attract people to the waterfront and achieve a desirable waterfronts.

\subsubsection{Uses and Activities}

The waterfront has a variety of land uses along its perimeter. To the north (waterfront), there are a lot of consecutive land uses; such as the Anfoushy Cultural Center, boat workshops, local club, children education centre and a huge sand public beach that serves as an attractive recreation area. The other street side has mixed land uses with residential area. The residential area contains ground floor cafes and restaurants with some street seating. Retail consists of many simple commercial shops and other service-related storefronts that add to the unique traditional style of the area and to reach unique designs to the Bahary Waterfront only. The most effective way to create a livable city and make an attractive urban form is by increasing activities. There are a lot of activities such as social and sports club, cinema and services like hospital and mosque. In addition, the waterfront thrives day and night throughout the year by integrated seasonal activities during different feasts that make users feel welcome and safe.

\subsubsection{Comfort and Image}

Bahary Waterfront has a different experience, due to its historical background and uses that create a strong sense of place. The Anfoushy citizens are enjoying the waterfront at the sunset and at night-time to meet each other. Fishing and boat industries are the primary activities in this area. The sense of smell and taste are characteristic to the study area and are shaped by the primary activities as the space can be understood through the sense and create a mental map. These senses are used to clarify and survive the life of the urban space to provide a unique and dynamic place to attract a range of people, they also should define people's experience and keep people coming back. By analyzing the buildings conditions, there is no 


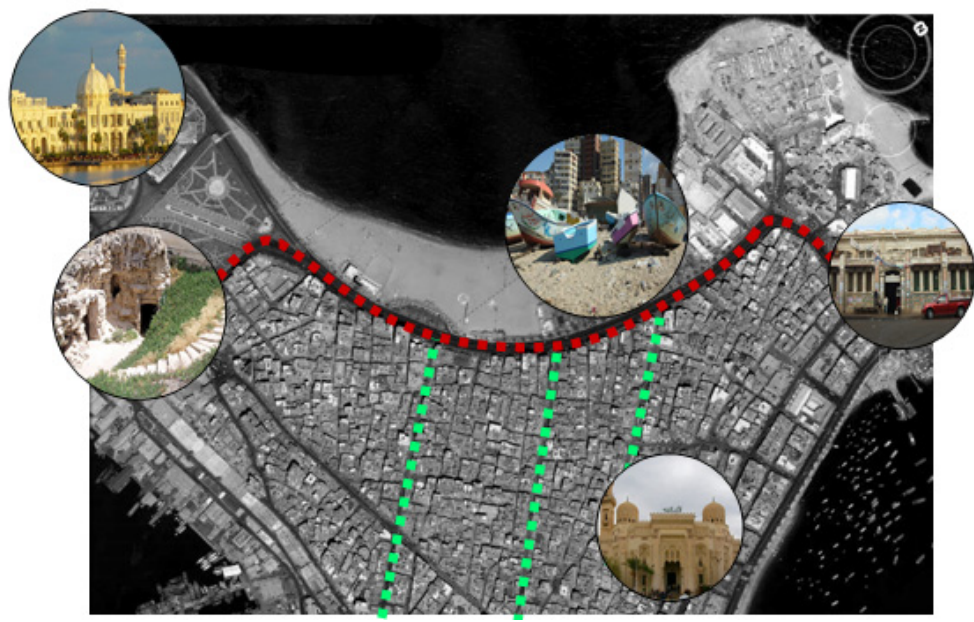

Fig. 11 Map showing the site accessed by the different paths of the study area.

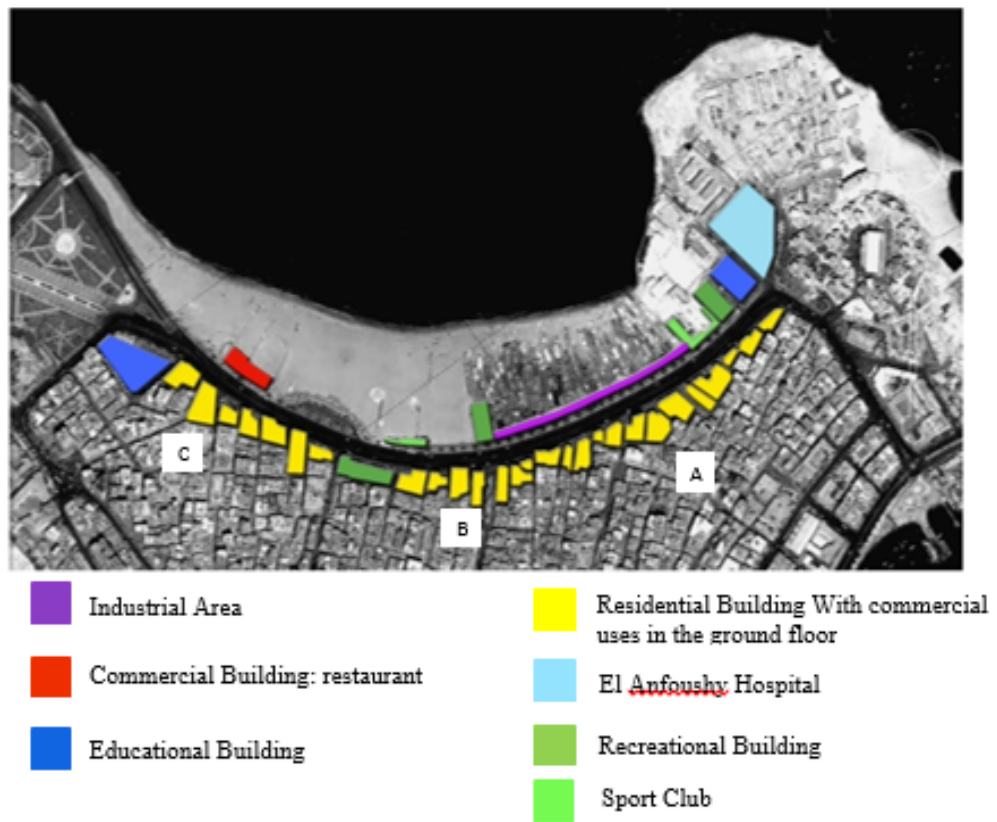

Fig. 12 Map showing the land use of the study areas.

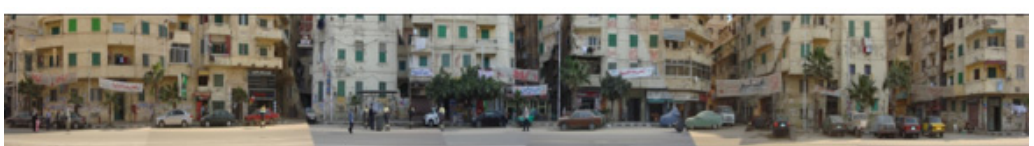

Zone A

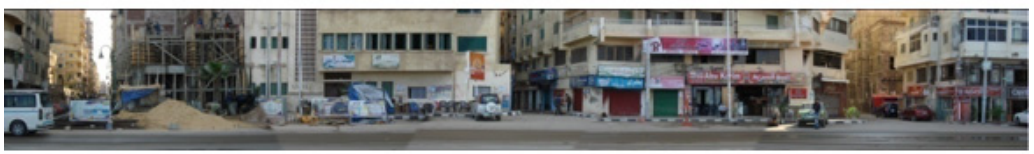

Zone B

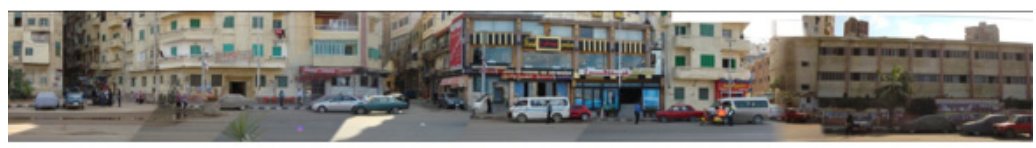

Zone C

Fig. 13 The study area is divided into three zone to show the different land uses. 

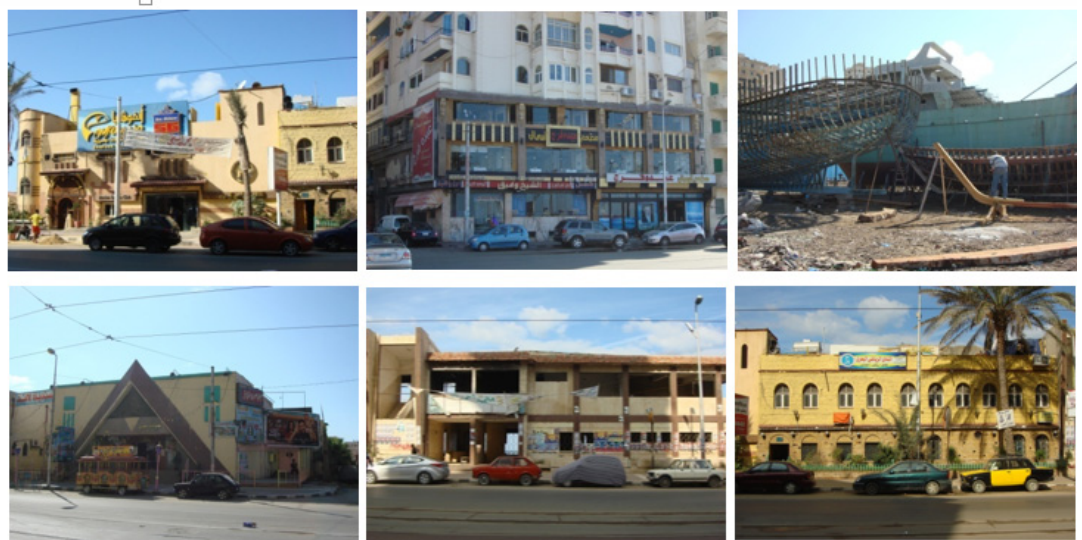

Fig. 14 Pictures of some activities by order: Anfoushiya Fish restaurant; Farag Fish and El Sheikh Wafik restaurants; Boat Workshops; El Anfoushy Cimena; Marine Sport Club; Child Club.
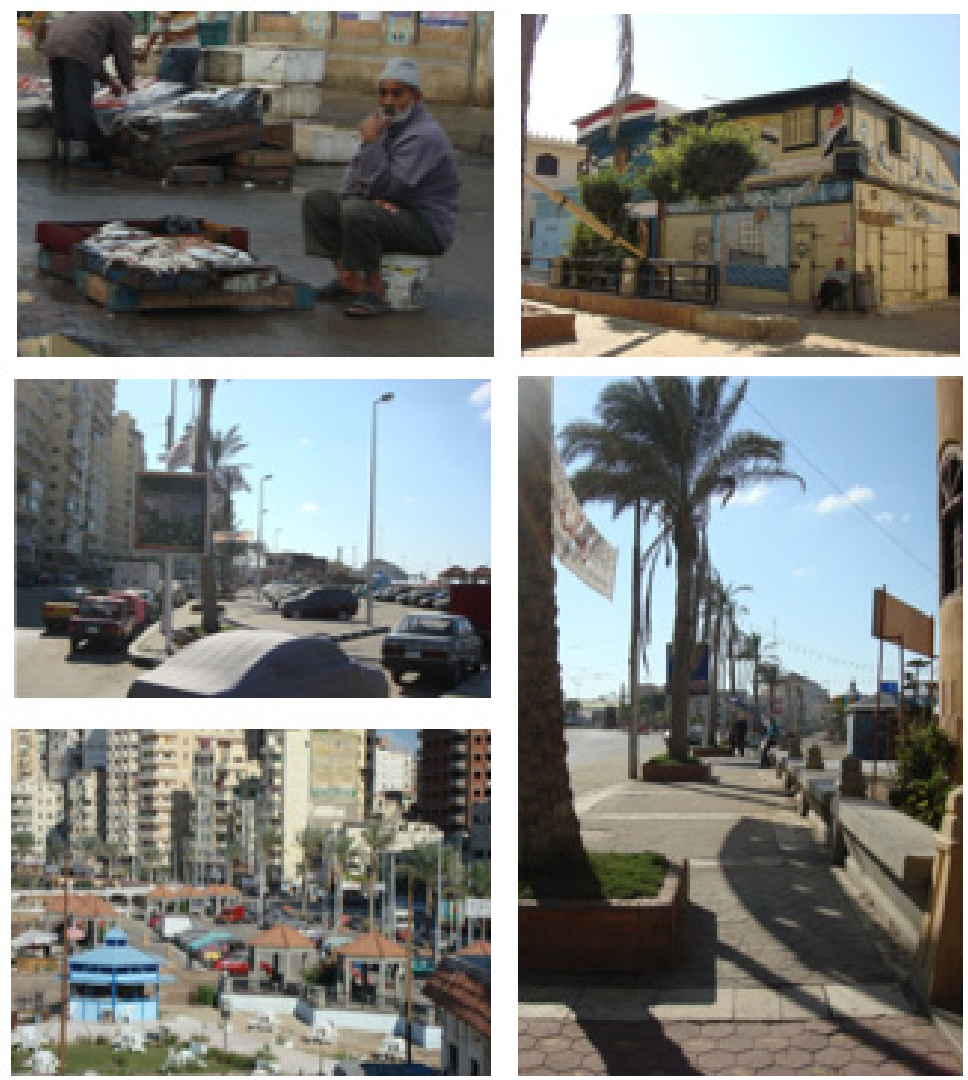

Fig. 15 Pictures showing different images in Bahary.

architectural style and character and buildings do not respect the building regulation. Although landscape element, amenities and furniture like seats, lighting units and sheds are used to provide comfort, social interaction but they are not well designed and organized. Also, there is a lack in parking areas.

In Kasr Ras El Tin Street, the Mediterranean Sea shore at Anfoushy Bay forms a strong edge. Also, the main path of the study area is the Kasr Ras El-Tin Street that connected Ras El-Tin Palace, The Anfoushy Cultural Centre and the Ptolemaic tombs which present the landmark of the area. In addition, small districts are formed along the street such as El Sayala, El-Hagary, Armed Forces residential compound and Bahary areas. At The Anfoushy Fish Market, there is a node with a number of visitors. 


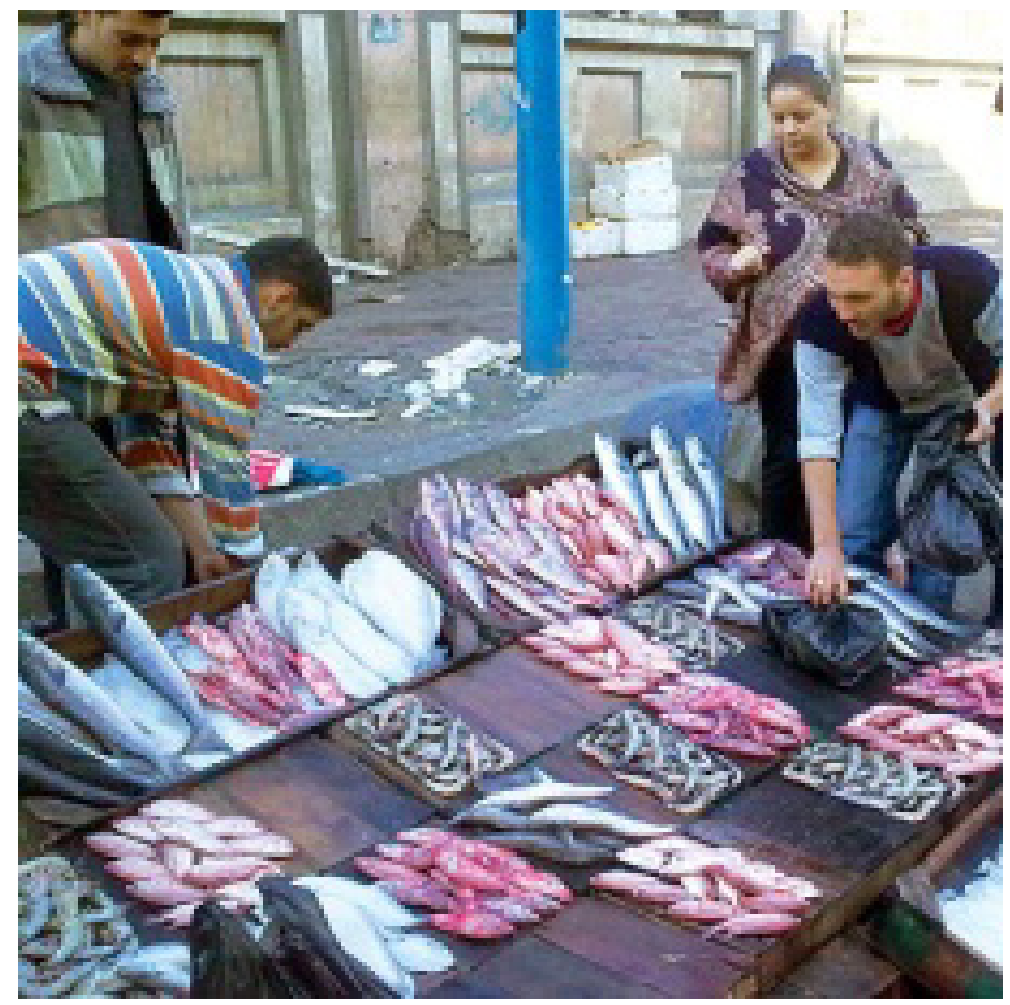

Fig. 16 The primary job in this area.

\subsubsection{Sociability}

Fishing and boat industries which are the primary activities, give a local identity and character to Bahary and offer a lot of job opportunities to the resident. Also, the old fish market is one of the main heritages building in this area. In addition, there are a lot activities, such as restaurants and marine center, based on the primary activities.

\section{Conclusions}

After analyzing the study area of Bahary Waterfront, several conclusions of the existing conduction have been highlighted, and some problems can be reached.

\subsection{Problems related to Access and Linkages}

Due to the variety of mean of transport in the study area, the movement is not organized and overlapped.

The secondary streets are very narrow and in a bad condition

Public access is not comfort and safe due to the lack of integration between the two sides of the waterfront.

\subsection{Problems related to Uses and Activities}

Although the district is considered as one of the important archeological site, but is not given enough attention.

The recreational uses located along the waterfront are very poor and limited.

The uses and activities are not homogenous distributed along the waterfront.

There are a mismatching between the function and activities of the area.

\subsection{Problems Related to Comfort and Image}

Some of the buildings are in a bad condition and do not have architecture style and details.

The parking areas are not enough and they are along to the waterfront.

The palm lined the promenade, impede the pedestrian walk.

The street furnitures like the sheds and seats are not well arranged in the area, and there is a very long 
distance between the street furniture.

\subsection{The Absence of the View of the Waterfront and the Public Art}

Although this area has a different sense and very rich of opportunities but it is not well exploited.

\subsection{Problems Related to Sociability}

The public goals are not achieved.

The management of the community vision does not take in consideration the public goal.

\section{Recommendations}

According to the previous results and problems of the case study, the following recommendations are set to improve the Bahary Waterfront:

(1) Access and linkages recommendations

- Providing public access to the shoreline that is supported by corridors and that establishes convenient connections to the other side of the waterfront and to adjoining streets that extends from the street grid of the city;

- The creation of public transit routes that provide easy transit to the waterfront from the city center;

- The creation of "nodes" along the waterfront and providing pedestrian linkages between public access nodes;

- Separating the movement of the pedestrian and vehicle by changing their paths and increasing different crossing points between the two side of the waterfront and bridges and tunnels;

- Adding a bicycle lane way and large promenade with well organized street furniture's;

- Creating floating promenades and platforms to define a new path and edge with the waterfront;

- Developing the secondary streets that connect the Bahary waterfront the city center.

(2) Uses and activities recommendations

- After analyzing the activities and the uses of Bahary Waterfront, it can be divided in three zones which are: Zone A represents commercial and residential zone, Zone B is recreational and residential area and Zone $\mathrm{C}$ is a historical area as it is can approach to the Ras el Tin Palace;

- Arranging of productive and compatible activities with the renewed context to ensure the diversity in the zone's economy;

- The water sheet and the shoreline should be reserved for water uses and public access;

- The ground floors of buildings should to reserve for recreational uses and the facilities of public accommodation;

- Devising a master plan of land use that blends the values of old and new structures and uses of Bahary.

(3) Comfort and image recommendations

- The using of the landmarks of this area revived the interest of the city's heritage;

- Reinforcing the attributes of the central area which is closely linked to the heart of the city;

- Creating well organized street furniture along the waterfront such as seating, shelters with good and comfortable material;

- Providing parking areas away from the waterfront.

(4) Sociability recommendations

- The public participation of the local population is important to achieve their needs and to make their own environment with the purpose of keeping alive the memory and preserving the identity of Bahary;

- The need of coastal management to address to the unplanned urban growth to ensure the harmonious development of human activities while protecting the submerged remains of the ancient city.

\section{References}

[1] Eves, C., Yassin, A., and McDonagh, J. 2011. "Waterfront Development for Residential Property in Malaysia." Queensland University of Technology. Accessed March 27, 2013. http://eprints.qut.edu.au.

[2] Ryckbost, P. 2005. "Redeveloping Urban Waterfront Property." University of Michigan. Accessed April 14, 2005. http//www.umich.edu.

[3] Breen, A., and Rigby, D. 1996. The New Waterfront: A 
Worldwide Urban Success Story. North America: McGraw-Hill.

[4] Wood, R., and Handley, J. 1999. "Urban Waterfront Regeneration in the Mersy Basin, North West England." Environmental Planning and Management 42: 565-80.

[5] Goodwin, R. F. 2009. "Redeveloping Deteriorated Urban Waterfronts: The Effectiveness of U.S. Coastal Management Programs." Coastal Management 27: 239-69.

[6] Gospodini, A. 2001. "Urban Waterfront Redevelopment in Greek Cities." Cities 18: 285-95.

[7] Abouelfadl, H. F. 2002. "Developing the Urban Surroundings of the Mahmoudia Canal: A Case Study of Elnozha District." Thesis, Alexandria University.

[8] Tibbalds, F. 2001. Making People Friendly Towns. England: Spon.

[9] Coggan, A., and Kelly, G. 2007. Quality of Life and Sustainability on the Central Coast. Report of CSIRO
Sustainable Ecosystems.

[10] Hancock, T. 2000. Quality of life indicators and the DHC. Ontario: Health Promotion Consultant

[11] Eurostat. 2014. "Quality of Life (QOL)-DATA." Accessed November 1, 2011. http://ec.europa.eu/ eurostat/web/gdp-and-beyond/quality-of-life/data.

[12] Project Public Spaces. 2009. "What Is Place Making." Accessed December 31, 2009. http://www.pps.org.

[13] Gold, H. 2002. Urban Life and Society. New Jersey, USA: Prentice Hall.

[14] Ragheb, A. R. 2014. “Alexandria's Eastern Entrance: Analysis of Qaitbay Waterfront Development." International Journal of Civil, Environmental, Structural, Construction and Architectural Engineering 8 (8): 865-74.

[15] Tsukio, Y. 1984. Waterfront. Tokyo: Process Architecture Pub. Co.

[16] Tour Egypt. 2011. "City of Alexandria in Egypt." Accessed August 28, 2011. http://www.touregypt.net. 